\title{
Stopping or Decreasing Opioid Therapy in Patients on Chronic Opioid Therapy
}

Joseph V. Pergolizzi · Giustino Varrassi · Antonella Paladini •

JoAnn LeQuang

Received: June 25, 2019 / Published online: August 3, 2019

(C) The Author(s) 2019

\section{ABSTRACT}

With the rising concerns about long-term opioid use, particularly in patients with chronic noncancer pain, more and more patients are being considered for decreased doses or discontinuation of opioid therapy. This is a challenging clinical situation for both patient and clinician and should be presented in a shared decision-making model so that the patient understands the risks of opioid therapy and how the therapy will be discontinued. The patient should be aware of the long-range plan and its milestones. It is imperative that alternate pain control treatments be made available to the patient early, and that the patient never feels abandoned by the healthcare team. There can be many barriers in shared decision-making and multiple discussions between patient and

Enhanced Digital Features To view enhanced digital features for this article go to https://doi.org/10.6084/ m9.figshare.8975750.

J. V. Pergolizzi · J. LeQuang ( $\varangle)$

NEMA Research, Inc, Naples, FL, USA

e-mail: joannlequang@gmail.com

G. Varrassi

Paolo Procacci Foundation and World Institute of Pain (WIP), Rome, Italy

A. Paladini

Department of MESVA, University of L'Aquila, L'Aquila, Italy provider may be required. Opioid use should not be decreased sharply or discontinued abruptly, but should be gradually decremented in a process known as tapering. Tapering should be systematic and planned in advance with the patient knowing the steps. Slow tapers (over months) are more comfortable for the patients but may not always be appropriate. There is guidance for planning the taper and the patient should be closely monitored throughout this process. If withdrawal symptoms occur, they can be managed, for example, with lofexidine. Patients should get full support as they explore new pain control options. For patients who have opioid use disorder, addiction counseling may be appropriate. Navigating opioid discontinuation can be slow work, but optimal results occur when the healthcare team works together and respectfully with the patient.

Keywords: Discontinuation of opioids; Opioid tapering; Opioid therapy; Opioid weaning; Opioid withdrawal; Opioid withdrawal symptoms; Reducing opioids

\section{INTRODUCTION}

The 2016 publication of the Centers for Disease Control and Prevention (CDC) guidelines for primary care physicians prescribing opioid therapy to treat noncancer pain in chronic pain 
patients advised prescribers to limit the daily dose of opioids in chronic therapy to under 90 morphine mg equivalents (MME) per day and to discontinue opioid therapy in patients who are no longer effectively treated with this regimen [1]. Recent changes to these guidelines have caused further confusion among clinicians as the CDC "walked back" some of their initial recommendations [2]. Unfortunately, the CDC has not offered guidance or insight into the often-challenging series of steps on how to reduce or even discontinue long-term opioid therapy. The discontinuation or reduction of opioid therapy after long-term exposure can be a long, slow, and difficult process for both patient and clinician. The abrupt discontinuation or even a sudden substantial dose reduction in opioid therapy for a patient on long-term (or even mid-term) opioid treatment can precipitate distressing and severe withdrawal symptoms and often causes an intense, seemingly irresistible craving for the drug that can drive patients to seek illicit or at least inappropriate sources for more opioids. Some chronic pain patients on a long-term opioid regimen have found themselves "abandoned" by physicians who refuse to prescribe opioid analgesics or who abruptly reduce their doses, leaving them with little explanation, no game plan, and inadequate analgesia. The consequences of inadequate pain control are far from trivial and may be difficult for those without chronic pain to fully comprehend. Patients with uncontrolled pain may experience limited function, social isolation, an inability to work or go about their activities of everyday living, disrupted sleep, diminished libido, and reduced quality of life.

Pain control is more than just a regulation of nociception resulting in a decrease in pain intensity. A patient in chronic pain who experiences analgesia also experiences mitigation of a number of experiential symptoms-the profound emotional relief from depression, the alleviation of fear and anxiety, soothing of sensations of suffering, the restoration of emotional equilibrium, the confidence of regained function, and the like. This relief provides the patient with a significant neurological "reward." It should be noted that the neural pathways associated with reward are distinct from pain pathways [3-5] and opioids can affect both. This importance of separate pain and reward pathways may explain why many individuals derive pain relief from medical marijuana although it offers no appreciable direct effect on pain pathways-but it does trigger reward pathways and in that way may provide relief from the emotional component of pain. Opioid analgesia not only provides pain relief, it directly affects the reward pathways and relieves the negative aspects associated with the pain experience [6]. These different neural pathways for reward versus analgesia may explain why some individuals are at higher risk for opioid use disorder than others. It goes beyond the scope of this article to more fully address the complex biopsychosocial phenomenon of opioid use disorder as a clinical condition unto itself.

There is likewise a strong link between untreated chronic pain and depression that involves the neural networks of the brain [7] as much as the sense of despair from living a life reduced by physical suffering [8]. So vital is analgesia for the well-being of many chronic pain patients that any disruption to their pain control medications can provoke anxiety and fearfulness that they may hide from healthcare professionals to avoid being labeled as "drug seekers." Unrelieved chronic pain has been associated with suicidal ideation [9], and people in chronic pain are $40 \%$ more likely to have suicidal ideation and/or attempt suicide than those without chronic pain [10]. Patients taking opioids may report anxiety, depression, sleep disorders, and other conditions, but these are likely to be chronic pathologies of different etiology and should be diagnosed and treated separately.

For patients on chronic opioid therapy who are appropriate candidates for a decrease in or discontinuation of therapy, it is important for clinicians to approach this situation both carefully and systematically. Patient education, professional compassion, and clinical patience are vitally important for safe, effective decreases in opioid therapy. It is our goal in this commentary to describe a methodology for decreasing or discontinuing opioid therapy. Abruptly stopping the drug and failing to communicate with the patient about the 
process are not options. We propose a series of steps that are necessary in effective opioid discontinuation: shared decision-making, tapering, clinical monitoring, managing withdrawal symptoms (if needed), pain control, and addiction therapy (if appropriate).

This article is based on previously conducted studies and does not contain any studies with human participants or animals performed by any of the authors.

\section{SHARED DECISION-MAKING}

Shared decision-making is increasingly upheld to be an important aspect of modern patientcentric healthcare but there is a dearth of training options for clinicians who seek to effectively involve their patients in making informed choices about their own care [11]. Shared decision-making about opioid therapy may be particularly challenging because patients may have medical as well as nonmedical motivations about taking opioids, the latter of which they may try to conceal. The shared decision-making model is based on frank and confidential conversation with the patient in a supportive atmosphere. In the case of opioid therapy, the clinician should explain the risks of long-term opioid therapy, including side effects, respiratory depression, immune suppression, hypogonadism, opioid-induced constipation, opioid-induced hyperalgesia, tolerance, and opioid use disorder (OUD). There may also be looming regulatory or reimbursement restrictions on chronic opioid therapy, which can also be discussed with the patient. While these are real and even frightening considerations for some patients, it is crucial that they understand they will not be abandoned by the clinical practice, that other effective pain control methods are available, and that the clinical team will work with them throughout the process-which may be lengthy. Patients with OUD should be educated and made aware that OUD is a medical consideration rather than a moral failing; they should be encouraged to talk openly with the clinical team about issues they might have relating to OUD. During this process, it may take multiple conversations before patients develop enough trust in the clinical team to fully articulate all of their concerns. It is not unusual to encounter patients who may be ashamed or afraid to reveal that they secretly wonder whether or not they have become addicted.

Patients on long-term opioid therapy likely have one or more of the following fears, although only the first one is universally considered medically acceptable: fear of uncontrolled pain, loss of mood-stabilizing effects, fear they will be deprived of "feeling normal," fear that they have become addicted (and fear of going through withdrawal), and the fear they will lose the drug's psychoactive effects. If they suspect they have OUD, they may be extremely worried about withdrawal symptoms or confused and embarrassed about being a "drug addict." The clinician may need to discuss these point by point with the patient in order to present appropriate options. These options include other ways to manage moderate to severe pain, coping skills, psychological support, treatment for specific mental health disorders (such as anxiety or depression), ways to reduce and stop opioid consumption with minimal adverse effects, and addiction counseling (if appropriate) [12-14]. In weighing the options, the clinician should describe which and how these alternative approaches may better serve the patient. It is also useful to discuss the limitations and adverse effects associated with opioid therapy, with which the patient may be all too aware.

Shared decision-making is not necessarily fast decision-making, and time-pressed clinicians may sometimes wish that they could short-circuit the decision-making process. For the clinical team, shared decision-making may be both rewarding and protective of the patient, although it may also sometimes be perceived as a burden [15]. However, time invested upstream in building a "team approach" and consensus to limit opioid use may pay off with better and more effective results downstream and save time as the patient goes through the step-bystep process of tapering and discontinuation. Even when patients are given generous time and thorough, patient-centric information to better understand the risks of opioid therapy 
and the options they have, there may still be some barriers to shared decision-making (see Table 1).

Shared decision-making is actually a form of coaching, during which the clinician tries to improve the patient's knowledge and perceptions to guide them toward a range of reasonable, health-affirming choices that align with their own personal goals and values [16]. A practical strategy to guide such sessions is to provide the patient with information and ask a series of questions. While the clinician may have a desired course of action, during shared decision-making, it is important to listen to the patient's concerns, fears, and objectives so that the therapy plan can be tailored to meet the needs of the individual patient. Shared decision-making can be empowering to patients, and it has been shown that shared decisionmaking strategies may confer improved outcomes, particularly but not exclusively on disadvantaged patients [17].

In some shared decision-making settings, it may be appropriate for the clinician to offer reasons to consider opioid tapering and/or discontinuation, which may include patient safety, OUD risk, changes in patient's pain or status, the availability of better or safer pain control options, enhancing the patient's immune system, avoiding opioid-associated side effects, or other factors. It may also be helpful to explain what is not at issue, for example, in some cases a patient's opioids may be reduced not because the clinician is concerned about abuse or diversion but rather safety or side effects. By tailoring the discussion to the patient rather than offering a generic list of reasons to change the opioid prescription, the patient may be more responsive or at least feel that the clinician understands his or her individual situation.

Clinicians may find that patients on opioids for many years may be reluctant to consider life without opioids. The long-term exposure may cause them to argue that they know what they're doing, opioids have worked well for years, and that their multi-year use proves they are not at elevated risk from opioid treatment. Patients tend to see things through the lens of their own experience and not be particularly swayed by epidemiological data [18]. See Table 2.

It would be disingenuous to maintain that all shared decision-making conversations are agreeable. Patients may feel hurt, angry, abused, maligned, misunderstood, judged, and sometimes may "threaten" to obtain illegal drugs if denied their prescriptions. Patients may feel singled out or accused of some kind of wrongdoing. Some may secretly feel ashamed and lash out at clinicians. Others may be unaware of the dangers of opioid therapy and react negatively, thinking the whole situation is being blown out of proportion. In fact, the entire discussion about drug discontinuation can be problematic because when patients are prescribed an appropriate and clinically indicated medication and are satisfied with it, rarely is it ever taken away. Since fear of pain and loss of clinical support is often a paramount concern for these patients, it may be helpful if alternative pain control regimens are introduced early in the conversation [19]. Patients should be reassured that the clinical team will not abandon them during or after the transition.

At the very least, a cogent patient whose long-term opioid therapy is to be reduced or discontinued should be informed about the process, the reasons for the changes, and how the transition is to be accomplished. Patients with cognitive deficits pose special challenges in this area and the use of opioids in this population requires special consideration that goes beyond the scope of this article [20]. Patients should feel that they have access to reasonable clinical and psychological support during the transition [18]. Once an agreement about changes to opioid therapy has been reached, the patient should be educated about the concept of opioid tapering. At this point, new pain control strategies should be discussed, ideally involving a multidisciplinary approach to pain management. Patients may be referred to a pain specialist, addiction expert, psychologist, psychiatrist, or other counselor to help navigate the transition away from opioids and toward other pain relief. Patients may also benefit from referrals to physical or occupational therapists; some patients at this point may be receptive to 
Table 1 Shared decision-making can be time-consuming and clinicians may encounter any of several barriers described below

\begin{tabular}{|c|c|c|}
\hline Barrier & Possible approach & Comment \\
\hline $\begin{array}{l}\text { Low health } \\
\text { literacy }\end{array}$ & $\begin{array}{l}\text { Provide patients with information, ideally in written } \\
\text { form to take home } \\
\text { Include family members in the discussions if they are } \\
\text { interested and especially if they have good health } \\
\text { literacy }\end{array}$ & $\begin{array}{l}\text { Low health literacy does not necessarily mean low } \\
\text { interest }\end{array}$ \\
\hline $\begin{array}{l}\text { Apathy or } \\
\text { disinterest }\end{array}$ & $\begin{array}{l}\text { Emphasize why opioid therapy must be re-evaluated } \\
\text { now (overuse, OUD, institutional or other } \\
\text { restrictions) } \\
\text { Continue the discussion at intervals, be patient }\end{array}$ & $\begin{array}{l}\text { Patients may be confused or lack understanding of } \\
\text { what is going on and may be more unaware of } \\
\text { changes in prescribing practices than apathetic }\end{array}$ \\
\hline $\begin{array}{l}\text { Ulterior } \\
\text { motives }\end{array}$ & $\begin{array}{l}\text { Foster a trusting, confidential rapport with patients } \\
\text { so they can be honest about what opioids really } \\
\text { mean to them }\end{array}$ & $\begin{array}{l}\text { Patients must trust that the clinical team will not } \\
\text { abandon them, even if they have OUD or admit } \\
\text { they like psychoactive effects }\end{array}$ \\
\hline $\begin{array}{l}\text { Overt } \\
\text { addiction }\end{array}$ & $\begin{array}{l}\text { Work with patients to describe the numerous risks } \\
\text { involved with OUD } \\
\text { Reassure patients that withdrawal can be managed so } \\
\text { that symptoms are reduced, if not altogether } \\
\text { eliminated (if they work with the clinic rather than } \\
\text { try to quit on their own) }\end{array}$ & $\begin{array}{l}\text { While many people with OUD adopt a non- } \\
\text { repentant posture, they are quite aware of the } \\
\text { downsides of addiction and may secretly wish to } \\
\text { quit } \\
\text { Some patients with OUD may lack the confidence to } \\
\text { try to quit or believe it is impossible } \\
\text { Withdrawal is a source of great fear for those with } \\
\text { OUD. With proper care, withdrawal symptoms can } \\
\text { be minimized or even avoided }\end{array}$ \\
\hline $\begin{array}{c}\text { Chemical } \\
\text { coping }\end{array}$ & $\begin{array}{l}\text { Be open and nonjudgmental in discussing mental } \\
\text { health with the patient and explain there are better } \\
\text { and more effective ways of dealing with problems } \\
\text { like anxiety, depression, and so on }\end{array}$ & $\begin{array}{l}\text { Some patients may be reticent to discuss mental } \\
\text { health concerns and the clinical team must work to } \\
\text { create a supportive, trusting relationship to allow } \\
\text { patients to disclose such issues } \\
\text { Some individuals may feel ashamed or embarrassed } \\
\text { that they cannot manage everyday life or stress } \\
\text { without help }\end{array}$ \\
\hline $\begin{array}{l}\text { Mental } \\
\text { health } \\
\text { disorders }\end{array}$ & $\begin{array}{l}\text { Discuss mental health with the patient in a frank and } \\
\text { nonjudgmental way; ask about their mental health } \\
\text { history and a familial history of mental health } \\
\text { disorders } \\
\text { If they have or are currently being treated for a } \\
\text { mental disorder, consult with the other clinicians to } \\
\text { get a more holistic overview of the patient's } \\
\text { concerns }\end{array}$ & $\begin{array}{l}\text { Many patients with OUD have concomitant mental } \\
\text { health disorders } \\
\text { Mental health issues can be stigmatizing and } \\
\text { uncomfortable for patients to discuss }\end{array}$ \\
\hline
\end{tabular}

Shared decision-making involves allowing both patient and prescriber to come together to reach informed decisions about treatment that take the patient's goals, fears, and objectives into account 
Table 2 Reasons to limit opioid therapy that may be relevant to the shared decision-making process

\section{Reason to decrease or discontinue opioid therapy \\ Opioids depress the respiratory system and there is a real risk for injury or even death \\ Opioids are powerful drugs and it is more difficult for older individuals to properly metabolize drugs \\ Opioids suppress the immune system and make patients prone to infections and other illnesses}

Opioids cause chronic constipation in most patients and that, over the long term, opioids are not good for the digestive system or colon health

Even though patients may feel able to drive while taking an opioid, it is possible to get arrested for drugged driving by taking these opioids even if they are taken only as prescribed

Opioids diminish the sex drive-and it gets worse over time

Over time, opioids can actually lower the pain threshold, making pain worse and not better

There is not a lot of evidence that longterm opioids help chronic painopioids are better for short-term pain

People get used to taking opioids and that is not healthy-a person should not be taking these drugs just to "feel normal"
Supporting arguments

Patient may not understand the mechanism of respiratory depression and its potentially fatal consequences

Patient may not understand that the drug and body interact and this interaction changes with aging

Patient may not have made the connection between infection risk and compromised immune system from opioids

Most patients know this all too well but need to understand that chronic constipation has consequences beyond discomfort

Most patients and even clinicians are unaware of the potential legal risks of driving while taking an opioid, including prescription opioids under medical supervision

Most patients are aware of this but many not have associated it with opioid use

The condition, opioid-induced hyperalgesia, means that for some patients, taking opioids actually makes their pain worse

Sometimes reducing opioids results in a remarkable decrease in pain levels

There may be other pain control strategies that when used together or in concert are equally or more effective than opioids

This is an indirect and nonjudgmental way to broach the subject of OUD

\section{Particularly relevant to}

Sedentary patients, the disabled, smokers, and those with chronic respiratory conditions

Older patients

Patients who have already experienced infections, cellulitis, osteomyelitis, etc. likely related to opioid use

All patients but particularly those who have complained about opioidinduced constipation in the past

Patients who drive, especially those who must drive for their work or lifestyle

Younger patients, patients in active relationships

All patients, especially those who complain that their pain levels are increasing the more opioids they take

Patients with chronic pain who seem very concerned about pain levels or who are functionally limited by their pain

Patients with OUD or at risk for OUD

Patients who do not seem to have a reason for severe pain but take high doses of opioids 
Table 2 continued

\begin{tabular}{llc}
\hline $\begin{array}{l}\text { Reason to decrease or discontinue } \\
\text { opioid therapy }\end{array}$ & Supporting arguments & Particularly relevant to \\
\hline $\begin{array}{l}\text { Opioids are being watched more closely } \\
\text { these days which means that it must } \\
\text { be determined if they are really } \\
\text { needed or not }\end{array}$ & $\begin{array}{c}\text { Emphasize that the national public } \\
\text { health crisis of opioid overdose deaths } \\
\text { has caused official concern which they } \\
\text { may see in pharmacies, clinics, } \\
\text { hospitals, and other places }\end{array}$ & $\begin{array}{c}\text { Pealistic, pragmatic patients } \\
\text { misgivings about opioids }\end{array}$ \\
$\begin{array}{l}\text { Over time a person taking opioids will } \\
\text { build up tolerance so that the doctors } \\
\text { must keep increasing the dose-and } \\
\text { high-dose opioids can be dangerous, } \\
\text { even deadly }\end{array}$ & $\begin{array}{l}\text { aspect of opioid therapy-but it can } \\
\text { result in patients who need very high } \\
\text { doses of opioids just to maintain } \\
\text { ordinary pain control }\end{array}$ & $\begin{array}{c}\text { Patients on very long-term opioid } \\
\text { therapy }\end{array}$ \\
\hline
\end{tabular}

exploring nonpharmacological pain control strategies, such as meditation [21, 22].

\section{TAPERING}

In order to prevent withdrawal symptoms, opioids should be tapered rather than stopped abruptly. Patients should clearly understand why a tapering plan is in place and the various stages or milestones of the plan. The exact tapering plan must be individualized to the patient's needs and there is a paucity of guidance in the literature to help clinicians manage the process. However, there are some important considerations that can aid clinicians in mapping out the main steps of a taper plan and these plans can be adjusted as they move forward. Speed is not necessarily an advantage in opioid tapering unless there are overriding reasons to have the patient discontinue therapy quickly. Slow, gradual tapers are more comfortable for the patient and, as a rule of thumb, the longer the exposure to opioids, the longer the taper should take. A chronic opioid patient may rightfully need months, even years, to taper successfully and with minimal duress. A good plan for a slow taper is to decrease the patient's total daily dose of opioids by $5-20 \%$ every 4 weeks. If speed is not crucial or if the patient has been taking high doses of long-acting opioids for many years, the patient may be allowed to plateau at each step for a couple of months. A rapid taper might reduce opioids by 10-20\% every week. In the most rapid tapers, the opioid dose can be reduced by $20-50 \%$ at first and then decremented daily by about $10 \%$ [23] (see Table 3).

When initiating a taper, inform the patient that tolerance is lost quickly and they may start to lose their tolerance to higher doses of opioids in as briefly as a week or two. This means that they would put themselves at very high risk for an overdose if they resumed their old dose of opioids in the middle of a taper. Slower forms of tapering plans can be done on an outpatient basis and can be very suitable for compliant patients. Fast and ultra-rapid tapers may precipitate withdrawal symptoms, can be distressing to the patient, and may require inpatient care to be successful [23].

It may be helpful to rotate the opioid before or during a taper. In general, patients on longacting opioids will eventually be rotated to short-acting opioids as their dose is decreased. Patients may experience periods of difficulty during a taper; it is generally recommended in such instances to plateau at a particular dose and go more slowly than to push forward too rapidly and then need to ramp a dose upward [23].

Patients may seek to provide input to the tapering plan, in particular they may prefer a taper to be done over a long time and in small 
Table 3 Four main types of taper as described by the Veterans Affairs Administration [23]

\begin{tabular}{|c|c|c|c|c|}
\hline Taper & Dose reduction & Schedule & Notes & Comments \\
\hline Slowest & $2-10 \%$ & $\begin{array}{l}\text { Every } \\
\qquad 4-8 \text { weeks }\end{array}$ & $\begin{array}{l}\text { Particularly suitable for those who took high doses of } \\
\text { long-acting opioids for many years }\end{array}$ & $\begin{array}{l}\text { Pauses OK } \\
\text { Outpatient OK }\end{array}$ \\
\hline Slow & $5-20 \%$ & $\begin{array}{l}\text { Every } \\
4 \text { weeks }\end{array}$ & Most commonly used taper plan & \\
\hline Fast & $10-20 \%$ & Every week & May cause withdrawal symptoms & \multirow{2}{*}{$\begin{array}{l}\text { May require } \\
\text { inpatient stay }\end{array}$} \\
\hline $\begin{array}{l}\text { Ultra- } \\
\text { rapid }\end{array}$ & $\begin{array}{l}20-50 \% \text { for first dose, } \\
\text { thereafter } 10-20 \%\end{array}$ & Every day & Can be difficult for the patient & \\
\hline
\end{tabular}

Note that slower tapers are considered less stressful than more rapid ones

steps. This is actually a very reasonable plan for some patients. It may helpful if the clinician negotiates with the patient. The physician may offer a series of options and allow the patient to select personal preferences. For example, the physician might suggest that the patient has three choices: stay on the existing regimen but decrease the pill count from four a day to three a day, or change the pill dose so that there are still four pills a day but the total dose is reduced; the clinician may also suggest a change of drug, such as a switch from oxycodone to hydrocodone. In some cases, allowing patient input (such as sticking to the patient's preferred fourpill-a-day schedule) may make patients feel more respected and in control, and that, in turn, may make them more compliant [18]. There can be some latitude within a tapering plan that allows for patient input that will not compromise the taper and may optimize adherence.

\section{CLINICAL MONITORING}

The patient should be under close clinical supervision during a taper. This may mean weekly in-clinic visits for some patients or visits every few weeks (and always prior to the each decremental step). In some cases, a telephone call may take the place of a face-to-face visit [23]. As the tapering process can make patients feel particularly vulnerable, they should have recourse to talk to someone on the clinical team as needed, as specific questions, concerns, or even problems can emerge. Patients should know the key milestones in their taper, which may include dose (moving from 90 to $60 \mathrm{mg} /$ day), functional goals (for instance, ability to walk a certain distance), and pain metrics (keeping pain intensity levels down). Many patients report that their pain diminishes or at least does not increase during the taper, but this is not universal. If a decrease in pain intensity occurs, it should be discussed with the patient as it may be reinforcing to the notion of discontinuing opioids. Clinicians may ask during these visits about opioid-associated side effects (which may decrease with dose), general well-being, and how the patient feels moving forward to a state of reduced opioid dependence.

\section{MANAGING WITHDRAWAL}

Withdrawal symptoms are more likely to occur with rapid tapers or sudden large decreases in dose but may occur in any tapering opioid patient. Early withdrawal symptoms may emerge in days or even hours of each step-down dose and may include anxiety, insomnia, restlessness, short respirations, sweating, runny nose, watery eyes, and dilated pupils. Patients may also feel agitated, aggressive, and experience intense cravings for the drug. Late symptoms can occur days or weeks later and include runny nose, water eyes, excessive yawning, rapid breathing, tremors, muscle spasms, piloerection, nausea, vomiting, diarrhea, 
abdominal pain, chills, and fever. The exact symptoms and their severity vary among patients. In an abrupt withdrawal, these symptoms might include increased white blood cells. Prolonged symptoms have been reported weeks and even months later and these may include: fatigue, irritability, dysphoria, bradycardia, low body temperature, and insomnia. Intense craving for the drug is a prominent withdrawal symptom at all stages [23].

Withdrawal may be managed pharmacologically but opioids and benzodiazepines should be avoided. Lofexidine or clonidine may help mitigate certain autonomic symptoms associated with opioid withdrawal [24]. Myalgia may be managed with acetaminophen (paracetamol), or nonsteroidal anti-inflammatory drugs (NSAIDs). Antiemetics such as ondansetron may help curb nausea. Trazodone can be employed as a sleep aid and diarrhea can be treated with loperamide or bismuth subsalicylate [23].

Note that with a slow taper, withdrawal symptoms may be mild or not occur at all. In many cases, withdrawal symptoms are not life threatening, although patients may find them distressing and uncomfortable. Opioids with a long half-life such as methadone may be associated with more of a time lag between dose decrease and the onset of withdrawal symptoms [23].

\section{PAIN CONTROL}

With respect to pain control, it is important to recognize that pain is an emotional experience as well as a sensory perception. On a strictly sensory level, pain involves nociception or other sensory inputs processed by the neural networks. Clinicians typically use the intensity of this perception to measure pain on a scale, but such metrics represent just one single dimension of pain. Pain, particularly chronic pain, may involve a host of affective experiences, such as its unpleasant nature, particular aspects of the pain (suddenness, burning, tingling, throbbing), the affective experiences of that pain, and patient responses, which may range from limping or moaning to reducing activity to seeking analgesic medications. While the initial perception of pain is not a complex cognitive event, the emotional experience of chronic pain may be highly complex. This experience of pain may involve memory, cognition, evaluation, contextualization, and interpretation. The emotional experience of pain may tap into the patient's deep belief systems (the meaning of life, the nature of suffering, feelings of guilt or victimization) and mental stability (fear of the future, insecurity, anxiety, sense of loss, sense of failure, shame, worry about being a burden to the family, and so on). Patients dealing with moderate to severe chronic pain may also experience depression, negativity, marginalization, anger, discontent, and anxiety either on a transient or persistent basis. They may suffer social isolation or a deterioration of personal relationships.

However, long-term opioid therapy may be counterproductive in that over time, tolerance to the analgesic effects of opioids build up and psychological dependence may occur as well. Long-term exposure to opioids may lower the pain threshold $[25,26]$. This notion-that longterm opioid therapy can exacerbate chronic pain and its psychological challenges in a condition known as opioid-induced hyperalgesia $(\mathrm{OIH})$ - needs to be further elucidated. OIH has been described in the literature but may be challenging to diagnose in real-world clinical practice $[27,28]$. Since $\mathrm{OIH}$ is a counterintuitive concept, patients may discount its validity or be skeptical that opioids may be exacerbating their pain. When discontinuing opioids, alternate pain control strategies are required and should be discussed with the patient. Multimodal approaches may be the most effective, but the specific combination of treatments must be tailored to the needs, lifestyle, and preferences of the individual patient (see Table 4).

\section{ADDICTION TREATMENT}

Opioid use disorder (OUD) exists as a spectrum and can complicate exit strategies for opioid therapy. OUD is distinct from tolerance, which is the normal and expected response of a patient exposed to opioids for a prolonged period. However, there may be a gray area where 
Table 4 A short and not-exhaustive list of nonopioid pain therapies which may be used individually or in combination (multimodal approach) to address pain

\begin{tabular}{lll}
\hline Approach & Category & Specific applications \\
\hline Acetaminophen & Pharmacological & Musculoskeletal pain, headache \\
Acupuncture/acupressure & CAM & Targeted pain relief \\
Anticonvulsant & Pharmacological & Neuropathic pain \\
Antidepressant & Pharmacological & Analgesic \\
Aromatherapy & CAM & Relaxation \\
Cognitive behavior & Psychological & Coping skills, self-awareness, pain management \\
therapy & & \\
Counseling & Psychological & Coping skills, stress management \\
Diet & Nonpharmacological & Weight loss, healthier foods, improved digestion \\
Exercise & Lifestyle & Joint pain, weight loss, strengthening core muscles, other muscles \\
Massage & Nonpharmacological & Relaxation, muscle pain \\
Meditation & Nonpharmacological & Relaxation, coping skills \\
Muscle relaxer & Pharmacological & Muscle spasm, back pain \\
Music therapy & CAM & Relaxation \\
NSAID & Pharmacological & Musculoskeletal pain, inflammatory pain \\
Occupational therapy & Nonpharmacological & Functional improvements, muscle strengthening \\
Physical therapy & Nonpharmacological & Functional improvements, muscle strengthening \\
Sleep schedule & Lifestyle & Headache pain, overall wellness \\
Supplements & Nonpharmacological, & Specific supplements may be helpful such as turmeric for joint \\
CAM & pain \\
Weight loss & Lifestyle & Joint pain, muscle pain \\
Yoga & CAM & Joint pain, digestive problems \\
\hline
\end{tabular}

The list is presented in alphabetical order by approach $C A M$ complementary or alternative medicine

"normal" tolerance ends and true OUD begins, which has been described as "complex persistent dependence" [29, 30]. Overt or admitted OUD is a good reason to taper and discontinue opioid therapy [31], but not all patients will be forthcoming about opioid abuse. Indeed, some patients with frank opioid addiction may attempt to obscure it from the clinical team. When OUD is known or suspected, the patient may benefit from referral to a pain specialist, psychologist, psychiatrist, or addiction treatment program. Addiction is a complex biopsychosocial phenomenon, characterized by relapses, and it resists fast and simplistic solutions.

It is beyond the scope of this paper to address addiction diagnosis and treatment, but clinicians navigating opioid cessation with their patients should learn about local, regional, and national resources that specialize in addiction 
care. Treatment options may include inpatient residential programs (which can be expensive and for which patients may lack coverage) as well as outpatient treatments. Not all patients will require formal OUD treatment, but it may be important for those who do that they get assistance guiding them to appropriate treatment choices. Psychological counseling may be particularly helpful for some patients being weaned off opioids. OUD is a relapsing disorder, so it is important to understand that treatment for some individuals may never produce a "permanent cure" but will provide periods of respite.

\section{DISCUSSION}

Opioid therapy should never be started without an exit plan-clinicians should work closely with appropriate patients to trial an opioid analgesic and assess its effectiveness and tolerability at the outset and at frequent intervals if therapy is continued longer term. From clinical trials it is known that a subset of patients discontinue opioid treatment voluntarily because of opioid-associated side effects or because opioids do not effectively address their pain. Thus, opioids should be trialed when the patient and clinician determine that the benefits outweigh the risk but always with eyes open to the fact that they may be ineffective, not be well tolerated, or that the patient may in other ways not be suitable for opioid therapy. For some patients, opioids will offer valuable analgesic relief that can help them restore function and improve quality of life. Long-term opioid therapy remains controversial and is probably not advisable in most cases-however, each patient is unique. When it is appropriate to discontinue opioids after long-term exposure, important challenges are created for patients and clinicians. It may be helpful for clinicians if opioid products carried appropriate labeling to the effect that abrupt discontinuation may precipitate withdrawal symptoms and what tapering strategies to use if the drug is to be stopped. For one thing, clinicians require education about how to discontinue opioids and also require determination and dedication to work through this time-consuming and often challenging process with their patients. A shared decisionmaking paradigm along with a sensible tapering plan can be effective, but it is imperative that patients not feel abandoned or even neglected during this transitional phase-which can last months. Opioid therapy can create dependence, lead to OUD, and may arouse in the patient a range of emotional responses such as fear or shame. Opioid cessation can have serious and disturbing physical as well as psychological consequences for the patient; clinicians must have confidence in managing these myriad issues with their patients. That requires education and an individualized approach to therapy; it may necessitate a referral to suitable specialists.

The original CDC guidelines for generalpractice physicians about prescribing opioids issued in 2016 created a degree of confusion among providers. The 12 th point of the guidance assigned to primary-care physicians the responsibility to help their patients navigate opioid discontinuation and OUD without the CDC offering specific recommendations as to how this might be accomplished. A number of key opinion leaders promoted these guidelines in speaking engagements, which likely struck fear in prescribers rather than confidence that they would be successful and ethical in managing painful conditions. Many of these staunch advocates for strict enforcement of the CDC guidance drew considerable attention to the guidelines. Payers and insurance companies were then able to deploy these guidelines, in certain cases, as a justification for denying payment for pain control. Thus, some clinicians became understandably fearful of their legal exposure when offering patients pain control and decided to opt out of opioid-prescribing altogether-even when opioids were the optimal, evidence-based choice for certain patients. The 2016 guidelines did not take into account the medical needs of the very people it was supposed to help-pain patients. The fallout was devastating for many pain patients and their families who found themselves suddenly marooned by the healthcare system with no access to pain control. The CDC has since adjusted these recommendations and perhaps 
we are moving in the right direction now, but patients and prescribers still need clear guidance in terms of when and how to terminate or decrease long-term opioid therapy. The Food and Drug Administration might be able to play a pivotal role here with educational initiatives and revisions to product labeling.

Opioids are not the enemy. They are one of many products in our armamentarium against pain and must be treated with respect and used appropriately [32]. Denying opioid analgesia to patients in pain and with appropriate indications is not a viable solution to the opioid crisis, but neither is prescribing opioids without taking care to evaluate the entire realm of pain control strategies and individualize a pain control plan. Patients who are trialed on opioids will likely sooner or later need to discontinue opioids, and clinicians must be prepared for this event. The clinical commitment to patients on chronic opioid therapy must be to help them transition on and off opioid therapy as appropriate and with evidence-based approaches, patient education, and professional compassion.

\section{CONCLUSIONS}

Patients on mid- or long-term opioid therapy may require special care if it is determined that opioids should be discontinued. Abrupt cessation of opioid therapy can cause potentially lifethreatening withdrawal symptoms, induce intense drug cravings (which can drive patients to illicit drugs), and precipitate intense pain that can lead to functional deficits and psychological distress. Clinicians should learn how to manage patients transitioning off opioids. When possible, a shared decision-making model should be used to allow for patient concerns to percolate to the surface and to select appropriate options for the individual's unique situation and needs. A sensible systematic tapering plan should be put into place and the clinical team must be available to support the patient during these challenging months. The patient will likely require alternative pain control regimens and multimodal approaches can be highly effective in managing some types of pain. In some cases, clinicians may need to refer patients discontinuing opioids to specialists or addiction treatment programs.

\section{ACKNOWLEDGEMENTS}

Funding. No funding or sponsorship was received for the study or publication of this article.

Authorship. All named authors meet the International Committee of Medical Journal Editors (ICMJE) criteria for authorship for this article, take responsibility for the integrity of the work as a whole, and have given their approval for this version to be published.

Disclosures. Joseph V. Pergolizzi is a member of the journal's Editorial Board. Giustino Varrassi is the Editor-in-Chief of this journal. Antonella Paladini and JoAnn LeQuang have nothing to disclose.

Compliance with Ethics Guidelines. This article is based on previously conducted studies and does not contain any studies with human participants or animals performed by any of the authors.

Open Access. This article is distributed under the terms of the Creative Commons Attribution-NonCommercial 4.0 International License (http://creativecommons.org/licenses/ by-nc/4.0/), which permits any noncommercial use, distribution, and reproduction in any medium, provided you give appropriate credit to the original author(s) and the source, provide a link to the Creative Commons license, and indicate if changes were made.

\section{REFERENCES}

1. Dowell D, Haegerich TM, Chou R. CDC guideline for prescribing opioids for chronic pain-United States, 2016. JAMA. 2016;315(15):1624-45. 
2. Dowell D, Haegerich T, Chou R. No shortcuts to safer opioid prescribing. $\mathrm{N}$ Eng $\mathrm{J}$ Med. 2019;380:2285-7.

3. Leknes S, Brooks JC, Wiech K, Tracey I. Pain relief as an opponent process: a psychophysical investigation. Eur J Neurosci. 2008;28(4):794-801.

4. Leknes S, Berna C, Lee MC, Snyder GD, Biele G, Tracey I. The importance of context: when relative relief renders pain pleasant. Pain. 2013;154(3):402-10.

5. Navratilova E, Porreca F. Reward and motivation in pain and pain relief. Nat Neurosci. 2014;17(10):1304-12.

6. Manhapra A, Arias AJ, Ballantyne JC. The conundrum of opioid tapering in long-term opioid therapy for chronic pain: a commentary. Subst Abus. 2018;39(2):152-61.

7. Zis P, Daskalaki A, Bountouni I, Sykioti P, Varrassi G, Paladini A. Depression and chronic pain in the elderly: links and management challenges. Clin Interv Aging. 2017;12:709-20.

8. Sheng J, Liu S, Wang Y, Cui R, Zhang X. The link between depression and chronic pain: neural mechanisms in the brain. Neural Plast. 2017;2017:9724371.

9. CDC. Suicide rising across the US: more than a mental health concern. Vital Signs 2018; https:// www.cdc.gov/vitalsigns/suicide/. Accessed Feb 27, 2019.

10. Braden J, Sullivan M. Suicidal thoughts and behavior among adults with self-reported pain conditions in the national comorbidity survey replication. J Pain. 2008;9:1106-15.

11. Elwyn G, Frosch D, Thomson R, et al. Shared decision making: a model for clinical practice. J Gen Intern Med. 2012;27(10):1361-7.

12. Varrassi G, Marinangeli F, Piroli A, Coaccioli S, Paladini A. Strong analgesics: working towards an optimal balance between efficacy and side effects. Eur J Pain (London, England). 2010;14(4):340-2.

13. Pergolizzi JV, Paladini A, Varrassi G, Raffa RB. Change pain: ever evolving_an update for 2016. Pain Ther. 2016;5(2):127-33.

14. Varrassi G. Management of acute and chronic pain in the Italian setting and a look toward the future. Clin Drug Investig. 2009;29(Suppl 1):1-2 (Foreword).

15. Elwyn G, Frosch DL, Kobrin S. Implementing shared decision-making: consider all the consequences. Implement Sci IS. 2016;11:114.
16. Stacey D, Hill S, McCaffery K, Boland L, Lewis KB, Horvat L. Shared decision making interventions: theoretical and empirical evidence with implications for health literacy. Stud Health Technol Inform. 2017;240:263-83.

17. Comoy EE, Mikol J, Luccantoni-Freire S, et al. Transmission of scrapie prions to primate after an extended silent incubation period. Sci rep. 2015;5:11573.

18. Matthias MS, Johnson NL, Shields CG, et al. I'm not gonna pull the rug out from under you: patientprovider communication about opioid tapering. J Pain. 2017;18(11):1365-73.

19. Ashton-James CE, Chemke-Dreyfus A, Costa D, Glare P. Time for change: an experimental investigation of chronic pain patients' emotional and attitudinal responses to simulated opioid-tapering advice. Pain. 2019;160:1586-93.

20. Cravello L, Di Santo S, Varrassi G, et al. Chronic pain in the elderly with cognitive decline: a narrative review. Pain Ther. 2019;21:1-3.

21. Collen M. Operationalizing pain treatment in the biopsychosocial model: take a daily "swem"-socialize, work, exercise, meditate. J Pain Palliat Care Pharmacother. 2015;29(3):290-9.

22. Coaccioli S, Varrassi G, Del Giorno R, et al. Meditation as a useful chance for chronic pain decrease. J Psychiatry. 2016;19:3.

23. Affairs UDoV. Opioid taper decision tool. 2018; https://www.healthquality.va.gov/guidelines/Pain/ cot/VADoDOTCPG022717.pdf. Accessed April 9, 2019.

24. Pergolizzi JV, Rosenblatt M, Mariano DJ, LeQuang JA. Clinical considerations about opioid withdrawal syndrome. Pain Manag. 2019;9(2):111-3.

25. Roeckel LA, Le Coz GM, Gaveriaux-Ruff C, Simonin F. Opioid-induced hyperalgesia: cellular and molecular mechanisms. Neuroscience. 2016;338:160-82.

26. Weber L, Yeomans DC, Tzabazis A. Opioid-induced hyperalgesia in clinical anesthesia practice: what has remained from theoretical concepts and experimental studies? Curr Opin Anaesthesiol. 2017;30(4):458-65.

27. Yi P, Pryzbylkowski P. Opioid induced hyperalgesia. Pain Med (Malden, Mass). 2015;16(Suppl 1):S32-6.

28. Varrassi G, Fusco M, Skaper SD, et al. A pharmacological rationale to reduce the incidence of opioid induced tolerance and hyperalgesia: a review. Pain Ther. 2018;7(1):59-75. 
29. Ballantyne JC, Sullivan MD, Kolodny A. Opioid dependence vs addiction: a distinction without a difference? Arch Intern Med. 2012;172(17):1342-3.

30. Ballantyne JC. Assessing the prevalence of opioid misuse, abuse, and addiction in chronic pain. Pain. 2015;156(4):567-8.

31. CDC. Pocket guide: tapering opioids for chronic pain. 2018; https://www.cdc.gov/drugoverdose/ pdf/clinical_pocket_guide_tapering-a.pdf. Accessed April 15, 2019.

32. O'Brien T, Christrup LL, Drewes AM, et al. European Pain Federation position paper on appropriate opioid use in chronic pain management. Eur J Pain (London, England). 2017;21(1):3-19. 